\title{
Bundesgericht: mal hü, mal hott!
}

Die veröffentlichte Urteilsbegründung zum Zürcher Medikamentenstreit ist höchst fragwürdig. Richterliche «Praxisänderungen» müssen selbstverständlich jederzeit erlaubt sein. Wenn sich aber nichts verändert hat, ja sogar nochmals die gleiche Überprüfung vom gleichen Gericht vorgenommen wird, dann ist ein anderslautendes Urteil kaum zulässig. Genau dies ist beim jüngsten Bundesgerichtsentscheid zur Zürcher Medikamentenabgabe aber geschehen. Gegen das Urteil des Verwaltungsgerichts aus dem Jahre 1998, das die heutige Stadt-Land-Regelung als verfassungswidrig taxierte, klagte damals bereits ein Apotheker vor Bundesgericht. Diesem wurde das Recht aberkannt, das Gericht in dieser Sache überhaupt anzurufen. In der Folge wurden zwei Volksinitiativen lanciert, zwei Gesetzesänderungen diskutiert und zwei heissumstrittene Abstimmungen geführt. Das Volk sprach sich dabei zweimal deutlich für die ärztliche Medikamentenabgabe auf dem Land und in der Stadt aus. Nachdem die Zürcher Regierung diesen Wunsch endlich mittels einer Verordnung erfüllte, riefen einzelne Apotheker erneut das Bundesgericht an. Und siehe da! Dasselbe Gericht gewährte diesmal mit einer künstlich konstruierten Argumentation das Recht zur Anrufung. Und damit nicht genug, mit interpretationsbedürftigen Aussagen bezweifelt es gleich auch noch das Urteil des Verwaltungsgerichts. So schreibt es beispielsweise, die heutige Norm sei nicht «geradezu als verfassungswidrig einzustufen ...».

Mein Respekt vor dem höchsten Gericht ist auf den Nullpunkt gesunken. Wenn ein Gericht einmal hü und einmal hott zur gleichen Fragestellung sagt und wenn ein Gericht sich mit «Wischiwaschiaussagen» zu Verfassungsfragen äussert, dann ist es sich seiner hohen Aufgabe und Verantwortung anscheinend nicht bewusst. Diesen Vorwurf muss sich das Bundesgericht fortan gefallen lassen, stehen wir doch wieder am Anfang. So, als wenn seit 1998 politisch nichts geschehen wäre. Gegen ein solches Gericht sollte eigentlich eine Schadenersatzklage angestrengt werden. Dieses Urteil hätte nämlich schon bei der ersten Anrufung so gefällt werden können. Allen Beteiligten wäre viel Ärger, Zeit und Geld erspart geblieben. Ärzte würden bei einem solchen Verhalten wohl wegen «Kunstfehlern» verklagt werden. Und unsere Bundesrichter? Sie geniessen ihre «Unantastbarkeit». Zumindest bis zur nächsten Wahl!

Dr. rer. publ. HSG Sven Bradke, Geschäftsführer der Ärzte mit Patientenapotheke (APA) 